\title{
Arctigenin Inhibits Etoposide Resistance in HT-29 Colon Cancer Cells during Microenvironmental Stress
}

\author{
Sae-Bom Yoon and Hae-Ryong Park* \\ Department of Food Science and Biotechnology, Kyungnam University, Changwon 51767, Republic of Korea
}

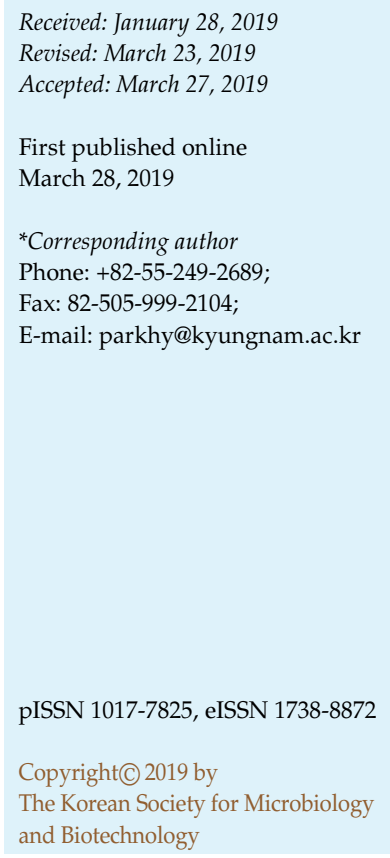

\begin{abstract}
Microenvironmental stress, which is naturally observed in solid tumors, has been implicated in anticancer drug resistance. This tumor-specific stress causes the degradation of topoisomerase II $\alpha$, rendering cells resistant to topoisomerase II $\alpha$-targeted anticancer agents. In addition, microenvironmental stress can induce the overexpression of $78 \mathrm{kDa}$ glucose regulated protein (GRP78), which can subsequently block the activation of apoptosis induced by treatment with anticancer agents. Therefore, inhibition of topoisomerase II $\alpha$ degradation and reduction in GRP78 expression may be effective strategies for inhibiting anticancer drug resistance. In this study, we investigated the active compound arctigenin, which inhibited microenvironmental stress-induced etoposide resistance in HT-29 cells. Arctigenin was also highly toxic to etoposide-resistant HT-29 cells, with an $\mathrm{IC}_{50}$ value of $10 \mu \mathrm{M}$ for colony formation. We further showed that arctigenin inhibited the degradation of topoisomerase II $\alpha$ and reduced the expression of GRP78. Thus, these results suggest that arctigenin is a novel therapeutic agent that inhibits resistance to etoposide associated with microenvironmental stress conditions.
\end{abstract}

Keywords: Anticancer resistance, microenvironmental stress, topoisomerase II $\alpha$, GRP78, arctigenin

\section{Introduction}

With advances in modern medicine, chemotherapy involving various anticancer agents can prolong the survival of cancer patients [1, 2]. However, long-term chemotherapy causes patients to acquire resistance to anticancer agents [3,4]. Solid tumors, of which the cores are located far from blood vessels, are often subjected to various microenvironmental stresses such as glucose deprivation, hypoxia, and other types of nutrient starvation, which are not commonly observed in normal cells [5-8]. These microenvironmental stress conditions in solid tumors induce two types of changes. The first change is the accumulation of proteasomes in the nucleus, which is followed by degradation of topoisomerase II $\alpha$ [9]. Thus, anticancer agents targeting topoisomerase II $\alpha$ become ineffective, resulting in drug resistance [10-12]. Topoisomerase II $\alpha$ plays an essential role in regulating the topological structure of DNA by breakage and reunion of double-stranded DNA [13]. Topoisomerase II $\alpha$-targeted anticancer agents, such as etoposide, stabilize the cleavable complex, an intermediate product of the topoisomerase II $\alpha$ catalyzed reaction [14].

The second change involves an increase in $78 \mathrm{kDa}$ glucose-regulated protein (GRP78) expression in the endoplasmic reticulum (ER) [15]. GRP78 is a molecular chaperone associated with nascent proteins; as proteins traverse the ER, GRP78 facilitates their folding and transport in an ATP-dependent manner [16]. GRP78 is induced by physiological stress and has been reported to be frequently overexpressed in tumors [17]. This phenomenon is attributed to the microenvironmental stress in solid tumors, which can activate the expression of the GRP78 gene [18]. As a molecular chaperone with protective properties, GRP78 protects cells against death, which is a regulated mechanism for cell survival, whereas in tumors, these properties potentially contribute to anticancer drug resistance [19]. 
<smiles>COc1cc(CC2COC(=O)C2Cc2ccc(OC)c(OC)c2)ccc1O</smiles>

Fig. 1. Chemical structure of arctigenin.

To identify a novel therapeutic drug, we constructed a system for screening compounds that inhibit drug-resistant cancer cells under microenvironmental stress conditions. We recently screened natural chemicals for their inhibitory activity against drug-resistant HT-29 human colon cancer cells under glucose deprivation induced by the addition of the chemical stressor 2-deoxyglucose (2DG). Using this screening system, we isolated arctigenin as an active compound from natural chemicals (Fig. 1) [20]. Arctigenin, a lignan of the phenylpropanoid class, has been reported to have various physiological activities such as antioxidant, anti-inflammatory, neuroprotective, and antitumor effects $[21,22]$. However, its inhibitory effect on anticancer drug resistance has not been reported.

Therefore, we investigated whether arctigenin inhibits anticancer drug resistance under microenvironmental stress conditions in solid tumors.

\section{Materials and Methods}

\section{Materials}

Arctigenin was purchased from Sigma Chemical Co. (USA), dissolved in dimethyl sulfoxide (DMSO) and stored at $-20^{\circ} \mathrm{C}$. Arctigenin was added to the cell culture medium such that the DMSO solvent composed less than $1 \%$ of the volume of the culture medium. 2DG, a chemical that induces microenvironmental stress conditions, was purchased from Sigma Chemical Co., dissolved in sterilized distilled water at a stock concentration of $2 \mathrm{M}$, and stored at $-20^{\circ} \mathrm{C}$. Etoposide, an anticancer agent that targets topoisomerase II $\alpha$, was purchased from Korea United Pharm., Inc. (Yeongi, Republic of Korea). Etoposide was dissolved in sterilized distilled water at a stock concentration of $10 \mathrm{mg} / \mathrm{ml}$ and stored at $-20^{\circ} \mathrm{C}$. RPMI1640 medium and penicillin/streptomycin were purchased from Gibco BRL (USA). Fetal bovine serum (FBS) was purchased from HyClone (USA). Other chemicals were of analytical grade or complied with the standards needed for cell culture experiments.

\section{Cell Culture and Treatments}

Human HT-29 colon cancer cells were obtained from Korean Cell Line Bank (Korea). The cells were maintained in RPMI1640 medium supplemented with $10 \%$ heat-inactivated FBS, penicillin $(100 \mathrm{U} / \mathrm{ml})$, streptomycin $(100 \mu \mathrm{g} / \mathrm{ml})$, and $2.0 \mathrm{mg} / \mathrm{ml}$ of $\mathrm{NaHCO}_{3}$ in a $37^{\circ} \mathrm{C}$ incubator (Sanyo, Japan) with $5 \% \mathrm{CO}_{2}$. To induce etoposide resistance, we applied microenvironmental stress conditions to cells by adding the chemical stressor 2DG (20 mM) to glucosecontaining culture medium. Arctigenin was immediately added to the cells at a final concentration of $100 \mu \mathrm{M}$. Etoposide $(10 \mu \mathrm{g} / \mathrm{ml})$ was then added under a full stress condition.

\section{Morphological Analysis}

To observe the cytotoxicity of arctigenin based on morphological changes, HT-29 cells were seeded at $2 \times 10^{5}$ cells $/ \mathrm{ml}$ in 6-well plates and incubated at $37^{\circ} \mathrm{C}$ with $5 \% \mathrm{CO}_{2}$ for $24 \mathrm{~h}$. The cells were then treated with $100 \mu \mathrm{M}$ of arctigenin under normal growth conditions. After incubation, the cellular morphology was observed using an inverted phase-contrast microscope (Nikon, Japan) at $100 \times$ magnification. Furthermore, to observe the resistance-inhibitory activity of arctigenin, the cells were seeded in 6-well plates and incubated at $37^{\circ} \mathrm{C}$ with $5 \% \mathrm{CO}_{2}$ for $24 \mathrm{~h}$. Next, the cells were pretreated with etoposide $(10 \mu \mathrm{g} / \mathrm{ml})$ in the presence of $2 \mathrm{DG}$ for $18 \mathrm{~h}$. After adding $100 \mu \mathrm{M}$ arctigenin to the cells followed by incubation for $24 \mathrm{~h}$, we microscopically observed changes in cellular morphology as described earlier in this section.

\section{Colony Formation Assay}

Cytotoxicity of arctigenin against HT-29 cells was measured by colony formation assay. HT-29 cells were seeded at $1 \times 10^{5}$ cells $/ \mathrm{ml}$ in 24-well plates and incubated at $37^{\circ} \mathrm{C}$ with $5 \% \mathrm{CO}_{2}$ for $24 \mathrm{~h}$. Under normal growth conditions, the cells were treated with $100 \mu \mathrm{M}$ of arctigenin. In addition, the sensitivity of HT-29 cells to etoposide was measured. HT-29 cells were prepared as mentioned earlier in this section and pretreated with etoposide $(10 \mu \mathrm{g} / \mathrm{ml})$ in the presence of 2DG $(20 \mathrm{mM})$ for $18 \mathrm{~h}$, followed by treatment with various concentrations of arctigenin for $24 \mathrm{~h}$. For both treatments, the cells were then diluted in fresh medium, reseeded at $1 \times 10^{3}$ cells $/ \mathrm{ml}$ in 6-well plates, and cultured under normal growth conditions for 7-8 days to form colonies [23]. Colonies were fixed with $10 \%$ formaldehyde, stained with $0.01 \%$ crystal violet, and counted. Cell survival was calculated by setting the survival of control cells as $100 \%$.

\section{Western Blot Analysis}

Whole-cell lysates were prepared by solubilizing cells in $1 \times$ sodium dodecyl sulfate (SDS) sample buffer $(62.5 \mathrm{mM}$ Tris-HCl, $\mathrm{pH}$ 6.8, 2\% SDS, 5\% 2-mercaptoethanol, and 10\% glycerol), as 
described [24]. Equal amounts of protein were resolved by $4-20 \%$ SDS-PAGE and transferred onto a nitrocellulose transfer membrane (Whatman $\mathrm{GmbH}$, Germany) for western blotting. Nitrocellulose membranes containing the transferred proteins were blocked in PBS containing 5\% non-fat dry skim milk and 0.1\% Tween 20 for $1 \mathrm{~h}$ at room temperature followed by incubation for $1 \mathrm{~h}$ with the respective primary antibodies, including mouse monoclonal antitopoisomerase II $\alpha$ (for detection of topoisomerase II $\alpha$; 1:500, BD Bioscience, USA), mouse monoclonal anti-KDEL (for detection of GRP78; $1: 500$, Stressgen, Canada), and mouse monoclonal anti- $\beta$ actin (for internal control; 1:1000, Sigma Chemical Co.), diluted in PBS-Tween buffer. Anti-mouse (Amersham Pharmacia Biotech, Japan) at 1:500 was used as a secondary antibody. Protein loading was controlled by probing the membranes with $\beta$-actin. The proteins on the membranes were detected with an enhanced chemiluminescence detection kit (Bio-Rad Laboratories, Inc., USA) and visualized using the Molecular Imager ChemiDoc (BioRad Laboratories, Inc.).

\section{Statistical Analysis}

All data presented were the means of three determinations. Data were analyzed by one-way analysis of variance (ANOVA) followed by Scheffe's test using the SPSS package for Windows (Version 14.0; USA). The differences were considered significant at $p<0.05$.

\section{Results and Discussion}

\section{Cytotoxicity of Arctigenin under Normal Growth Conditions}

To evaluate whether arctigenin has inherent cytotoxicity in HT-29 human colon cancer cells under normal growth conditions, we performed cell viability assays. First, the effects of arctigenin on the cellular morphology of HT-29 cells under normal growth conditions were determined by phase-contrast microscopy. As shown in Fig. 2A, after HT29 cells were exposed to $100 \mu \mathrm{M}$ of arctigenin for $24 \mathrm{~h}$ under normal growth conditions, arctigenin exhibited a weak inhibitory effect on cell proliferation, but no other cytotoxic effects such as cytoplasmic shrinkage were observed. We then examined the effects of arctigenin on cell viability using the colony formation assay. HT-29 cells were treated with $100 \mu \mathrm{M}$ arctigenin for $24 \mathrm{~h}$. As a result, we confirmed that arctigenin had little or no effect on HT29 cell viability under normal growth conditions (Fig. 2B).

These results suggest that arctigenin is not cytotoxic under normal growth conditions. We next determined whether arctigenin is effective in overcoming drug resistance induced by microenvironmental stress in colon cancer cells.

\section{Arctigenin Inhibits Etoposide-Resistant HT-29 Cells}

To evaluate the inhibitory effects of arctigenin on drug resistance during microenvironmental stress, we observed cellular morphological changes by phase-contrast microscopy. HT-29 cells treated with arctigenin $(10$ and $100 \mu \mathrm{M})$ were exposed to 2DG, which induces simulated hypoglycemia, to induce microenvironmental stress conditions and were then incubated with etoposide. As shown in Fig. 3, we confirmed that HT-29 cells acquire resistance to etoposide during microenvironmental stress (Fig. 3d). However, acquired resistance to etoposide was blocked by pretreatment with arctigenin. As a result, many of the cells exhibited cytoplasmic shrinkage and either detached from each other or floated in the medium (Figs. 3e and 3f).

We next examined the effects of arctigenin on the viability of etoposide-resistant HT-29 cells during microenvironmental stress conditions. 2DG treatment, used to induce microenvironmental stress conditions, had no effects on cell viability but induced resistance to etoposide in HT-29 cells. Arctigenin was highly toxic to 2DG-induced etoposide-resistant HT-29 cells in a dose-dependent manner,
A

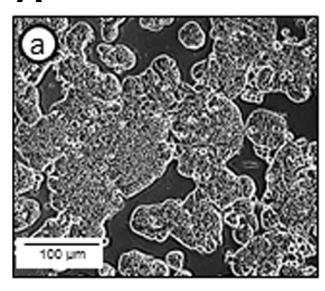

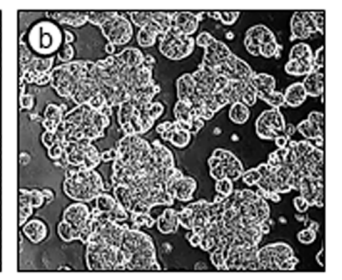

B

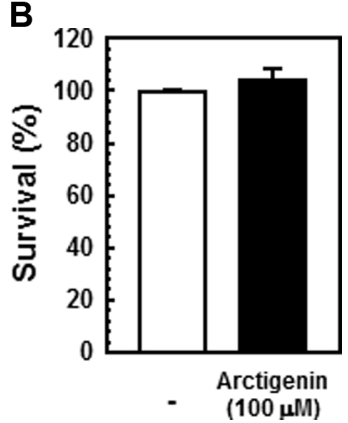

Fig. 2. The cytotoxicity effects of arctigenin in HT-29 cells under normal growth conditions.

The cells were exposed to $100 \mu \mathrm{M}$ of arctigenin for $24 \mathrm{~h}$ under normal growth conditions. (A) Photographs were taken using phase-contrast microscopy at $100 \times$ magnification (a, control; b, $100 \mu \mathrm{M}$ arctigenin). (B) After the colony formation assay, the survival rate was calculated based on the surviving colony number compared with the non-treated control. 

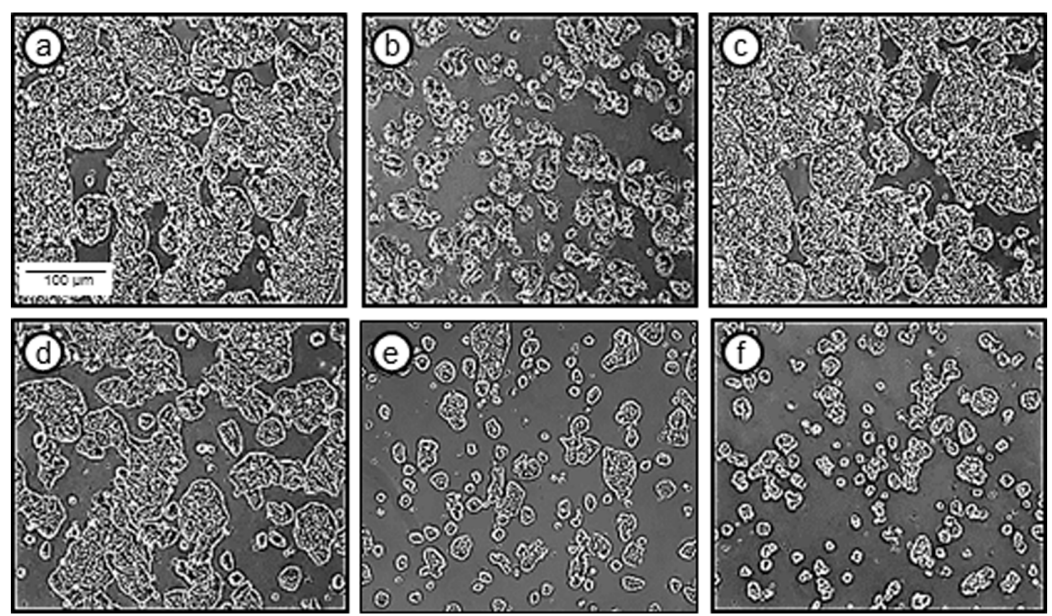

Fig. 3. Effects of arctigenin on morphological changes in etoposide-resistant HT-29 cells.

The cells were exposed to arctigenin $(10$ and $100 \mu \mathrm{M}), 2 \mathrm{DG}(20 \mathrm{mM})$, and etoposide $(10 \mu \mathrm{g} / \mathrm{ml})$, as described below (a, control; b, etoposide; c, 2DG; d, 2DG + etoposide; e, 2DG + etoposide + $10 \mu \mathrm{M}$ of arctigenin; f, 2DG + etoposide $+100 \mu \mathrm{M}$ of arctigenin). Photographs were taken at $100 \times$ magnification.

with an $\mathrm{IC}_{50}$ value of approximately $10 \mathrm{mM}$ (Fig. 4). These results indicated that arctigenin exhibits strong cytotoxic effects on etoposide-resistant HT-29 cells during microenvironmental stress conditions. These results suggest that arctigenin inhibits degradation of topoisomerase II $\alpha$ and

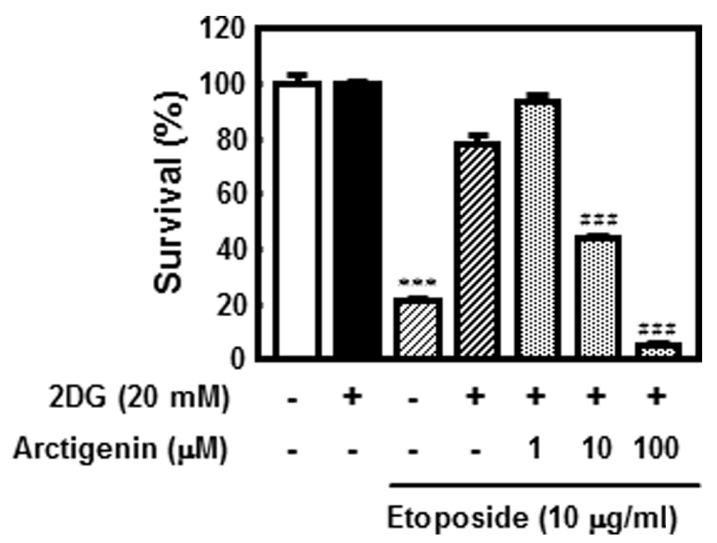

Fig. 4. Inhibitory effects of arctigenin on etoposide-resistant HT-29 cells.

The effects of arctigenin on viability in etoposide-resistant HT-29 cells were examined by colony formation assay. The cells were exposed to the indicated concentrations of arctigenin for $18 \mathrm{~h}$ in the presence or absence of 2DG $(20 \mathrm{mM})$. Non-treated cells were determined as normal growth conditions. During the last $4 \mathrm{~h}$ of treatment, cells were exposed $10 \mu \mathrm{g} / \mathrm{ml}$ of etoposide. Survival factors were calculated by setting each of the control survival rates as that under normal growth or microenvironmental stress conditions. ${ }^{* *} p<0.001$ compared with normal growth conditions. ${ }^{\# \#} p<0.001$ compared with microenvironmental stress conditions. expression of GRP78; thus, sensitivity to etoposide in colon cancer cells is increased only under microenvironmental stress conditions.

\section{Mechanistic Study of Arctigenin under Microenvironmental Stress Conditions}

Cancer cells were shown to be resistant to etoposide in microenvironmental stress conditions [6]. These conditions lead to the accumulation of proteasomes, which are multicatalytic protease complexes implicated in the degradation of topoisomerase II $\alpha$ in the nucleus [9]. As a result, etoposide loses its target, and these cancer cells become etoposide resistant [13]. In contrast, in response to microenvironmental stress, cancer cells up-regulate the expression of GRP78, which plays a role in protecting cancer cells against the toxic effects of anticancer drugs [19]. Therefore, we hypothesized that etoposide-resistant HT-29 cells under microenvironmental stress conditions can be controlled through the inhibition of topoisomerase II $\alpha$ degradation and down-regulation of GRP78 expression.

To evaluate the inhibitory effects of arctigenin on etoposide resistance, we examined the potential effects of arctigenin on topoisomerase II $\alpha$ and GRP78, two major proteins correlated with microenvironmental stress conditions in HT-29 cells, by western blot analysis. We found that arctigenin inhibits topoisomerase II $\alpha$ degradation under microenvironmental stress conditions in a dosedependent manner (Fig. 5A). Moreover, arctigenin induced the down regulation of GRP78 expression under microenvironmental stress conditions. However, arctigenin did 

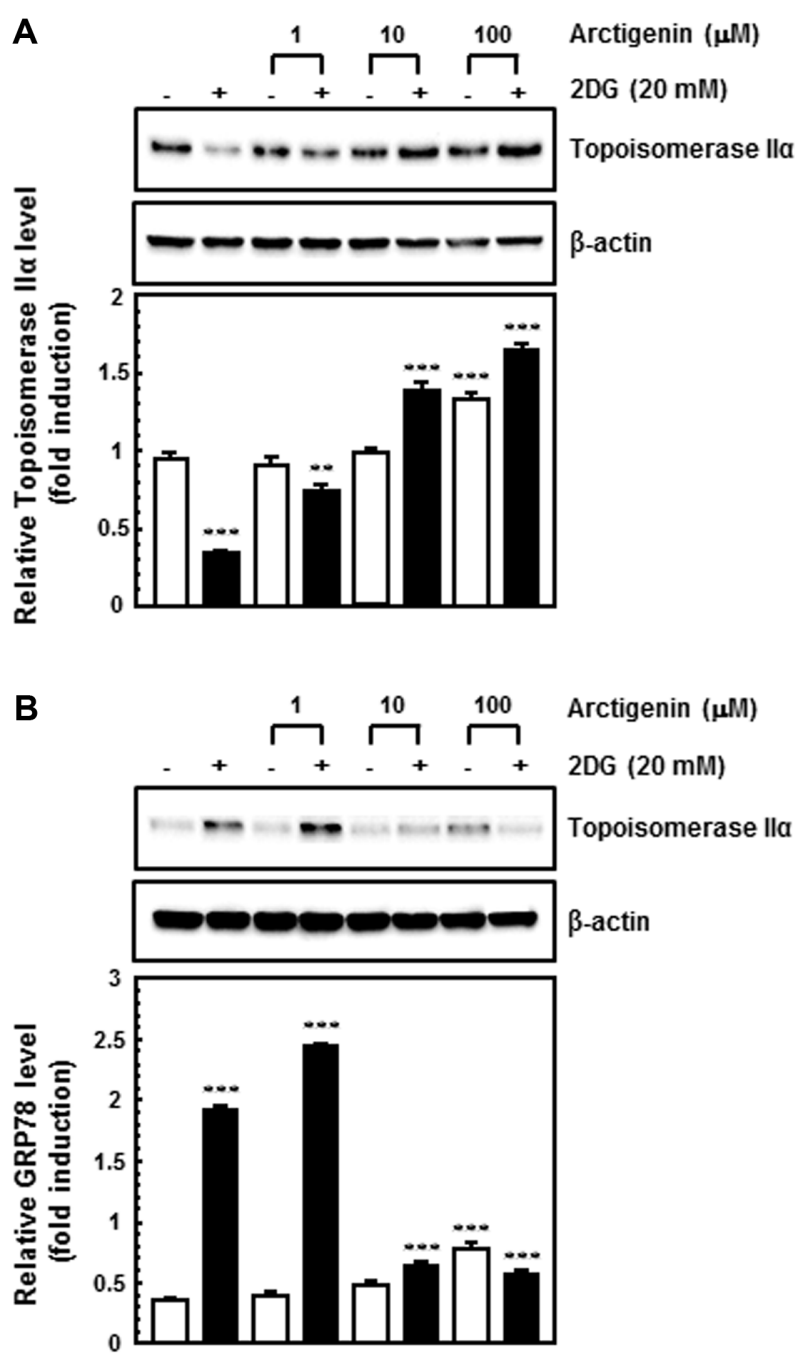

Fig. 5. Arctigenin suppressed the degradation of topoisomerase II $\alpha$ (A) and reduced the expression of GRP78 (B) in HT-29 cells under microenvironmental stress conditions.

Total cell lysates of HT-29 cells were prepared and subjected to western blot analysis using mouse monoclonal anti-topoisomerase II $\alpha$ antibody, and mouse monoclonal anti-KDEL antibody. HT-29 cells were treated with various concentrations $(1,10$, and $100 \mu \mathrm{M})$ of arctigenin for $24 \mathrm{~h}$ under $20 \mathrm{mM}$ of 2DG. $\beta$-Actin was measured as an internal loading control. ${ }^{* *} p<0.01$; ${ }^{* * *} p<0.001$ compared with normal growth conditions.

not dose-dependently affect the expression of GRP78 under normal growth conditions (Fig. 5B). These results indicated that arctigenin inhibits degradation of topoisomerase II $\alpha$ and induces the down-regulation of GRP78 only during microenvironmental stress conditions.

Taken together, we demonstrated that drug resistance related to etoposide under microenvironmental stress conditions can be controlled by arctigenin. Although additional research is needed to delineate the relative contribution of the pathways involved, our results suggested that arctigenin is a potential novel therapeutic agent for inhibition of anticancer drug resistance associated with microenvironmental stress. Importantly, arctigenin had no cytotoxic effects under normal growth conditions. These results have stimulated our interest and will promote further studies of arctigenin and in vivo resistance to topoisomerase II $\alpha$-targeted chemotherapy in cancer models.

\section{Acknowledgments}

This work was supported by Kyungnam University Foundation Grant, 2015.

\section{Conflict of Interest}

The authors have no financial conflicts of interest to declare.

\section{References}

1. Goodman GE, Yen YP, Cox TC, Crowley J. 1987. Effect of verapamil on in vitro cytotoxicity of adriamycin and vinblastine in human tumor cells. Cancer Res. 47: 2295-2304.

2. Ahn HJ, Kim JY, Lee CH, Song IS, Liu KH. 2008. Screening of chemosensitizer candidates using natural extracts. J. Life Sci. 9: 1244-1248.

3. Shen DW, Goldenberg S, Pastan I, Gottesman MM. 2000. Decreased accumulation of $\left[{ }^{14} \mathrm{C}\right]$ carboplatin in human cisplatin-resistant cells results from reduced energy dependent uptake. J. Cell Physiol. 183: 108-116.

4. Goto S, Kamada K, Soh Y, Ihara Y, Kondo T. 2002. Significance of nuclear glutathione $S$-transferase pi in resistance to anti-cancer drugs. Jpn. J. Cancer Res. 93: 1047-1056.

5. Axelson H, Fredlund E, Ovenberger M, Landberg G, Pahlman S. 2005. Hypoxia-induced dedifferentiation of tumor cells-A mechanism behind heterogeneity and aggressiveness of solid tumors. Semin. Cell DevBiol. 16: 554-563.

6. Brown JM, Giaccia AJ. 1998. The unique physiology of solid tumors: opportunities (and problems) for cancer therapy. Cancer Res. 58: 1408-1416.

7. Tomida A, Tsuruo T. 1999. Drug resistance mediated by cellular stress response to the microenvironment of solid tumors. Anticancer Drug Des. 14: 169-177.

8. Acker T, Plate KH. 2002. A role for hypoxia and hypoxiainducible transcription factors in tumor physiology. J. Mol. Med. 80: 562-575. 
9. Vaupel P, Yhews O, Hoeckel M. 2001. Treatment resistance of solid tumors: role of hypoxia and anemia. Med. Oncol. 18: 243-259.

10. Chen AY, Liu LF. 1994. Mechanisms of resistance to topoisomerase inhibitors. Cancer Treat. Res. 73: 263-281.

11. Coux O, Tanaka, Goldberg AL. 1996. Structure and functions of the $20 \mathrm{~S}$ and $26 \mathrm{~S}$ proteasomes. Annu. Rev. Biochem. 65: 801847.

12. Pommier $Y$, Leteurtre F, Fesen MR, Fujimori A, Bertrand R, Solary E, et al. 1994. Cellular determinants of sensitivity and resistance to DNA topoisomerase inhibitors. Cancer Invest. 12: $530-542$.

13. Wang JC. 1996. DNA topoisomerases. Annu. Rev. Biochem. 65: 635-692.

14. Froelich-Ammon SJ, Osheroff N. 1995. Topoisomerase poisons: harnessing the dark side of enzyme mechanism. J. Biol. Chem. 270: 21429-21432.

15. Ma Y, Hendershot LM. 2001. The unfolding tale of the unfolded protein pesponse. Cell 107: 827-830.

16. Mazzarella RA, Green M. 1987. Erp99, and abundant, conserved glycoprotein of the endoplasmic reticulum, is homologous to $90 \mathrm{kDa}$ heat shock protein (hsp90) and the $94 \mathrm{kDa}$ glucose-regulated protein (GRP94). J. Biol. Chem. 262: 74-108.

17. Choo SJ, Park HR, Ryoo IJ, Kim JP, Yun BS, Kim CJ, et al. 2005. Deoxyverrucosidin, a novel GRP78/BiP down-regulator, produced by Penicillium sp. J. Antibiot. 58: 210-213.
18. Yu JL, Coomber BL, Kerbel RS. 2002. A paradigm for therapy-induced microenvironmental changes in solid tumors leading to drug resistance. Differentiation 70: 599-609.

19. Fernandez PM, Tabbara SO, Jacobs LK, Manning FCR, Tsangaris TN, Schwarts AM, et al. 2000. Overexpression of the glucose-regulated stress gene GRP78 in malignant but not benign human breast lesions. Breast Cancer Res. Treat. 59: 15-26.

20. Umehara K, Nakamura M, Miyase T, Kuroyanagi M, Ueno A. 1996. Studies on differentiation inducers. VI. Lignan derivatives from Arctium fructus. (2). Chem. Pharm. Bull. 44: 2300-2304.

21. Zhao F, Wang L, Liu K. 2009. In vitro anti-inflammatory effects of arctigenin, a lignan from Arctium lappa L., through inhibition on iNOS pathway. J. Ethnopharmacol. 122: 457-462.

22. Zhang $N$, Wen $Q$, Ren L, Liang W, Xia Y, Zhang X, et al. 2013. Neuroprotective effect of arctigenin via upregulation of P-CREB in mouse primary neurons and human SH-SY5Y neuroblastoma cells. Int. J. Mol. 14: 18657-18669.

23. Ogiso Y, Tomida A, Tsuruo T. 2002. Nuclear localization of proteasomes participates in stress-inducible resistance of solid tumor cells to topoisomerase II-directed drugs. Cancer Res. 62: 5008-5012.

24. Ogiso Y, Tomida A, Lei S, Omura S, Tsuruo T. 2000. Proteasome inhibition circumvents solid tumor resistance to topoisomerase II-directed drugs. Cancer Res. 60: 2429-2434. 